Article

\title{
Effects of the Origin and Deacetylation Degree of Chitosan on Properties of Its Coatings on Titanium
}

\author{
Milena Supernak-Marczewska ${ }^{1}\left(\mathbb{D}\right.$ and Andrzej Zielinski ${ }^{2, *(\mathbb{D})}$ \\ 1 Quality and Materials, Department of Ship Manufacturing Technology, Gdansk University of Technology, \\ 80-233 Gdansk, Poland; milsuper@pg.edu.pl \\ 2 Department of Materials Engineering and Bonding, Gdansk University of Technology, \\ 80-233 Gdansk, Poland \\ * Correspondence: azielins@pg.edu.pl; Tel.: +48-501-329-369
}

Received: 13 December 2019; Accepted: 21 January 2020; Published: 23 January 2020

\begin{abstract}
The properties of chitosan coatings on titanium surfaces may be influenced by a variety of factors, including their chemical characteristics and the deposition method. The aim of this research was to determine the influence of a chitosan's origin (a type of shrimp) and deacetylation degree (DD), when deposited on a very smooth titanium surface, on adhesion and biological behavior. The tests were performed using chitosan of a degree of $87 \%$ or $84 \%$ of deacetylation and that originated from armor crabs or shrimp armor. The technology of fabrication of chitosan coatings was by surface polishing to a smooth surface, oxidation in air, and immersion in a chitosan solution. The surface topographies were analyzed with an atomic force microscope and their water contact angles were measured by a falling drop method with a goniometer. The bioactivity tests were done in in vitro on osteogenic cells, type MC3T3-E1, with a biological microscope. The abrasion of the coatings was examined using a nano tribotester. The obtained results revealed that the adhesion of the coatings onto a smooth, oxidized titanium surface is appropriate as they remain sufficiently adjacent to the surface after wear tests. The source of chitin has a significant influence on biological properties, and the deacetylation degree is much less critical. The performed tests demonstrated the crucial role that the source of chitosan and the applicability of the applied surface treatment play in the preparation of chitosan coatings.
\end{abstract}

Keywords: chitosan; titanium; coatings; hydrophobicity; bioactivity; adhesion

\section{Introduction}

Chitosan is a linear polysaccharide consisting of linked D-glucosamine with randomly located $\mathrm{N}$-acetyl-glucosamine groups. It is biocompatible, bioactive, and antimicrobial in water-insoluble form, and it can be quickly processed into membranes, films, gels and hydrogels, nanofibers, beads, nanoparticles, nanospheres, microspheres, microgranules, scaffolds, and sponges [1-5]. Chitosan is obtained by chemical or enzymatic deacetylation of chitin. The substrate is derived from the shells of shrimps, crabs, or crevettes [6] and found in different fungi, insects, and food [7]. Its medical applications are numerous and include delivery systems for growth factors, DNAs, and small interfering RNAs (siRNAs) [8], chitosan membranes in dental implantology and as scaffolds for producing artificial skin and cartilage $[9,10]$, wound dressings [3] and leather materials with an antimicrobial activity $[11,12]$, composite-polymer-based materials for bone repair [13-15], and as a support material for controlled drug and non-viral gene delivery [16].

One of the crucial technologies currently in development is obtaining chitosan scaffolds of better mechanical strength for use in bone or cartilage tissue regeneration. Thein-Han and Misra [15] fabricated chitosan scaffolds with nanohydroxyapatite (nanoHA) by freezing and lyophilization. These 
chitosan scaffolds had a highly porous structure, with pore sizes from 50 to $120 \mu \mathrm{m}$ and a compression modulus in the range of 6.0 to $9.2 \mathrm{kPa}$, and demonstrated a cell attachment and proliferation rate superior to those of pure chitosan. Another composite scaffold developed by Li et al. [13] consisted of a porous titanium (Ti) filled with a chitosan/hydroxyapatite (HA) sponge. Busilacchi et al. [17] investigated chitosan-chondroitin sulfate seeded with human stem cells, and showed it to be highly beneficial for enhancing the proliferation and differentiation of osteoblasts. Paluszkiewicz et al. developed a bioactive composite of chitosan and montmorillonite [18].

Chitosan can also be produced in gel form. A biocomposite comprised of preformed chitosan cryogel with dispersed biphasic calcium phosphate was proposed by Abueva et al. [19] for bone-filling material for stabilizing pathologic fractures. Hybrid hydrogels were prepared [20] by introducing nanoHA into a chitin solution, which increased about 10 times the compressive strength of chitin hydrogel. The synergy of chitosan with hyaluronic acid was shown by Muzzarelli et al. and used to regenerate hyaline cartilage [21].

Chitosan was well developed in membrane form for guided bone regeneration (GBR( for dental implantology. Asymmetric chitosan membranes were fabricated by Xu et al. [1] through liquid nitrogen quenching combined with lyophilization and cross-linking by sodium tripolyphosphate. In in vitro tests performed by Ma et al. [22], no dead cells were detected on the chitosan membrane. In work completed by Cheng et al. [23], nanoHA/chitosan composite membranes were prepared by solvent casting and evaporation methods, demonstrating that in vitro tests had no adverse effect on the cell morphology, viability, and proliferation. Novel chitosan/gelatin membranes were prepared [24] using a suspension of chitosan hydrogel mixed with gelatin.

The use of chitosan to form coatings on titanium was investigated to develop sufficient adhesion, biodegradability, biocompatibility, and bioactivity. The mechanism of chitosan deposition is determined by the surface state of the titanium, including surface chemistry, topography, surface charge (protonation), wettability, and roughness, as well as by deposition parameters [1,6]. The most popular methods use some toxic substrates to create sufficient adhesion between the chitosan and titanium surface by covalent bonds. Despite that, the adhesion strength was found to be quite small, between roughly 1 and $5 \mathrm{MPa}$. Chitosan coatings on titanium, made of $91.2 \%$ deacetylated chitosan, were chemically bonded to titanium coupons via silane-glutaraldehyde molecules [25]. The chitosan-coated surfaces exhibited a significantly higher contact angle, albumin adsorption, fibronectin adsorption, and cell attachment as compared to the control Ti sample. In other research of the same chitosan [26], the bond strength values of the coatings were estimated at 1.5-1.8 MPa, and the attachment and growth of rat osteoblast cells (UMR 106) were more significant on the chitosan-coated samples than on the uncoated titanium. Chitosan bonded to titanium via silane-glutaraldehyde molecules brought about slightly higher strength values between 2.2 and 3.8 MPa [27]. Another approach was based on a two-step process, which applied two different silane molecules and toluene as a solvent, resulting in coatings with a bulk adhesion strength of $19.50 \mathrm{MPa}[28,29]$. A silica xerogel/chitosan hybrid was applied to titanium at room temperature, resulting in a crack-free thin layer and excellent bone bioactivity [30]. In another research study [31], a biocompatible, biodegradable, and mechanically stable coating of a chitosan-polyvinyl alcohol polymer composite on titanium was produced. The surface roughness, contact angle, and surface zeta potential were markedly increased by the sulfuric acid treatment and the subsequent chitosan immobilization [32].

The impacts of deacetylation degree (DD) and chitin source on mechanical and biological behavior have yet to be extensively studied. As shown by Yuan et al. [27], the effect of DD on coating bond strength was found to be minor, and the molecular weight of the chitosan coatings after five weeks decreased less for higher DD chitosan coatings. In another publication [33], a higher DD facilitated attachment and proliferation of cells, but no induction of spontaneous osteogenic differentiation was observed. The cell adhesion was shown to increase with decreasing DD [34].

State-of-the-art reveals that chitosan may be a good substitute for currently used HA and nanoHA coatings on Ti implants, demonstrating the substantial biological activity and biocidal properties. 
These properties may critically depend on the chitosan's properties, and the latter may be determined by the chitosan's origin, DD, and surface preparation. The present research was aimed at assessing the influence of the DD and chitin source on the properties of chitosan membranes and coatings prepared in the same way on a polished and oxidized titanium surface.

\section{Materials and Methods}

\subsection{Materials}

Technical titanium $(0.1 \mathrm{C}, 0.3 \mathrm{Fe}, 0.015 \mathrm{H}, 0.03 \mathrm{~N}$, and $0.25 \mathrm{O}$ in wt \%, Ti the rest, according to the ASTM B265-20 [35]), delivered by Titanium Industries, was used as a substrate. Titanium specimens with dimensions of $10 \mathrm{~mm} \times 10 \mathrm{~mm} \times 2 \mathrm{~mm}$ were polished with abrasive grinding papers, No. 2400 as the last, subsequently cleaned in an ultrasonic bath in acetone, ethanol, and distilled water, and finally oxidized in laboratory air at $550{ }^{\circ} \mathrm{C}$ for $3 \mathrm{~h}$ to obtain the anatase oxide layer. The specimens were randomly chosen, with three replicates for each test.

Three forms of powdered chitosan differing in DD were tested and named DD 87\% sigma (Sigma-Aldrich, St. Louis, MO, USA), DD 87\%, and DD 94\% (Genis, Reykjavik, Iceland).

\subsection{Preparation of Chitosan Membranes and Coatings}

The chitosan membranes and coatings on titanium samples were prepared for tests. The chitosan membranes were made for each test based on a mixture of chitosan $(0.1 \mathrm{~g})$, acetic acid of analytical purity $(50 \mu \mathrm{L})$, and distilled water $(9.85 \mathrm{~mL})$. The mixture was stirred using a magnetic device to dissolve the chitosan powder completely. Next, the homogenization was made in a separator at $5000 \mathrm{rpm}$ for $1 \mathrm{~h}$. Portions of the homogenous solution were poured into six holes in a small laboratory, followed by drying in an incubator at $37^{\circ} \mathrm{C}$ for $24 \mathrm{~h}$. At the next stage, neutralization of transparent membranes was performed with a $0.5 \mathrm{M}$ sodium hydroxide $(\mathrm{NaOH})$ solution of analytical purity. The hydroxide solution was poured onto membrane surfaces and the specimens were placed in the shaker for $30 \mathrm{~min}$. After removing the excess of the neutralizing solution, the membranes were again put into the incubator for $12 \mathrm{~h}$ at $37^{\circ} \mathrm{C}$ in order to dry the specimens. Then, sterilization, using $70 \%$ ethanol of analytical purity poured onto membrane surfaces, was carried out for $30 \mathrm{~min}$. Afterward, the excess ethanol was removed from the membrane surfaces. The preparation of membranes was made separately for each form of chitosan. For the membranes, the surface topography, water contact angle, and some biological tests were carried out at the Innovation Center Iceland, Reykjavik, Iceland.

The preparation of the chitosan coatings on oxidized Ti samples was performed similarly. After solution preparation, the titanium specimens were immersed three times for each specimen. A single immersion time was $3 \mathrm{~min}$ and the time interval between subsequent immersions was $5 \mathrm{~min}$. After the last immersion, the samples were dried, the coatings were neutralized and sterilized, and the excess ethanol was removed for the membranes. For the coatings, wear tests and some biological tests were carried out.

\subsection{Examinations of Surface Topography and Morphology}

The surface topography of membranes was examined with the atomic force microscope (AFM), (Park Systems, XE-100 type, Suwon, Korea) at the Innovation Center Iceland. The non-contact mode, a scan distance of $5 \mu \mathrm{m}$, and frequency of $0.15 \mathrm{~Hz}$ were applied. The results were analyzed with the XEI Manual 1.7.6 software. The average roughness $R_{\mathrm{a}}$ was estimated.

The titanium surface's morphology and its chemical composition after gas oxidation of samples and before chitosan deposition were examined with the SUPRA 25 scanning electron microscope (SEM; Carl Zeiss AG, Dresden, Germany), equipped with an X-ray electron diffraction spectrometry (EDS; EDAX Inc, Oxford, Great Britain) facility, at the Innovation Center Iceland. 


\subsection{Measurements of Wettability of Chitosan Membranes}

The water contact angle on chitosan membranes was determined with the KSV-CAM 200 goniometer (KDSV Instruments, Helsinki, Finland) at the Innovation Center Iceland. A deionized water drop of $2 \mu \mathrm{L}$ in volume was used. The freely falling drop method was applied. Each angle value was calculated as a mean of nine independent test results.

\subsection{Measurements of Wear Resistance}

The wear resistance tests were performed on the coatings deposited on titanium samples with a CSM nano tribometer (CSM Instruments, Peseux, Switzerland) The specimens were cyclically pressed with a ceramic ball of $2 \mathrm{~mm}$ in diameter, at the following motion parameters: radius $1.5 \mathrm{~mm}$, ball rotation $90^{\circ}$, frequency $1 \mathrm{~Hz}$, and load $100 \mathrm{mN}$. Each test lasted 666 cycles. The change in depth and friction coefficient were measured during the test.

\subsection{Biological Tests}

The biological tests were performed at the Blood Bank, Landspitali University Hospital, Reykjavik, Iceland. The settlement of osteoblasts and their proliferation were examined, with the MC3T3-E1 osteoblasts used. The cells taken from living mice were stored at $-80^{\circ} \mathrm{C}$ and thawed in a water bath at $37^{\circ} \mathrm{C}$. One milliliter of thawed osteoblasts was mixed with $5 \mathrm{~mL}$ of a nutrient and centrifuged at $1750 \mathrm{rpm}$ for $5 \mathrm{~min}$. Afterward, the osteoblasts were incubated in 5000 cells on $1 \mathrm{~cm}^{2}$ in a culture vessel and placed in a plastic container together with $22.5 \mathrm{~mL}$ of the nutrient. Then, the box with cells was stored in the incubator at $37{ }^{\circ} \mathrm{C}$, a humidity $95 \%$, and in the presence of $5 \% \mathrm{CO}_{2}$. As the nutrient, $\alpha$-MEM solution (GIBCO ${ }^{\mathrm{TM}}$ ), with an addition of $10 \%$ of fetal bovine serum (FBS), $1 \%$ of penicillin, and $1 \%$ of streptomycin, was used. Observations of the behavior of cells on the titanium coatings were made every day and their nutrition every two days. The cell growth (number) was observed using the 4',6-diamidino-2-phenylindole (DAPI) and carboxyfluorescein succinimidyl ester (CFSE) reagents.

To verify the coverage of a titanium surface with chitosan coatings, the specimens were immersed after proliferation tests in a $2 \%$ alizarin red solution. The exposure time in the shaker was $20 \mathrm{~min}$. Then, the solution was removed, and each specimen was rinsed three times with distilled water. Finally, the samples were left to dry for $12 \mathrm{~h}$ in air.

\section{Results}

\subsection{Surface Topography of Oxidized Titanium}

The oxide layer was continuous, without any cracks and other defects (Figure 1). The chemical composition of the layer included titanium, oxygen, and traces of silicon (Si), which were likely left as a residue after polishing of the titanium surface (Figure 2).

\subsection{Surface Topography of Chitosan Membranes}

The topography of all membranes is shown in Table 1 and Figures $3-5$. The obtained results show that the chitosan forms thin, smooth coatings in the nanometric range.

Table 1. The average roughness $R_{\mathrm{a}}$ of chitosan membranes.

\begin{tabular}{cc}
\hline Chitosan Form & Roughness \pm Standard Deviation, $\mathbf{n m}$ \\
\hline DD 87\% sigma & $1.73 \pm 0.10$ \\
DD 87\% & $1.56 \pm 0.16$ \\
DD 94\% & $0.91 \pm 0.07$ \\
\hline
\end{tabular}




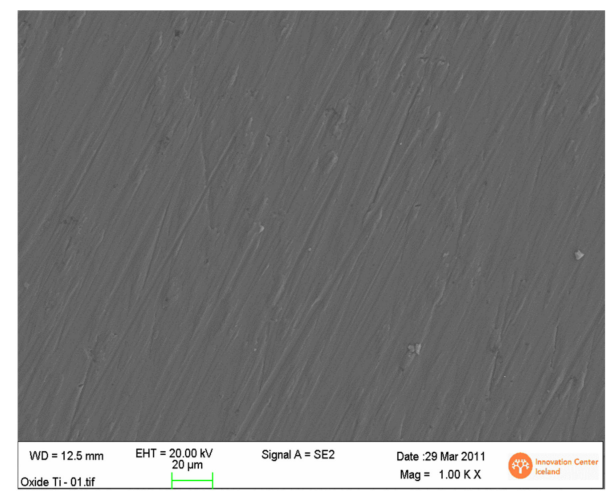

(a)

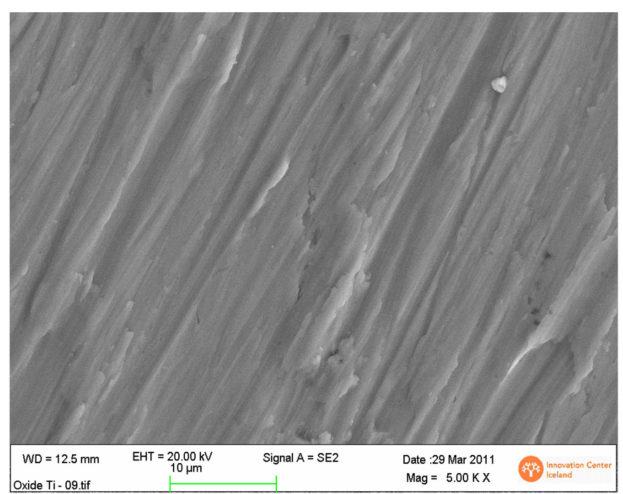

(b)

Figure 1. Surface topography after gas oxidation of titanium; two different magnifications the green bars of different magnifications of $20 \mu \mathrm{m}$ (a) and $10 \mu \mathrm{m}(\mathbf{b})$. The smooth traces after polishing are visible.
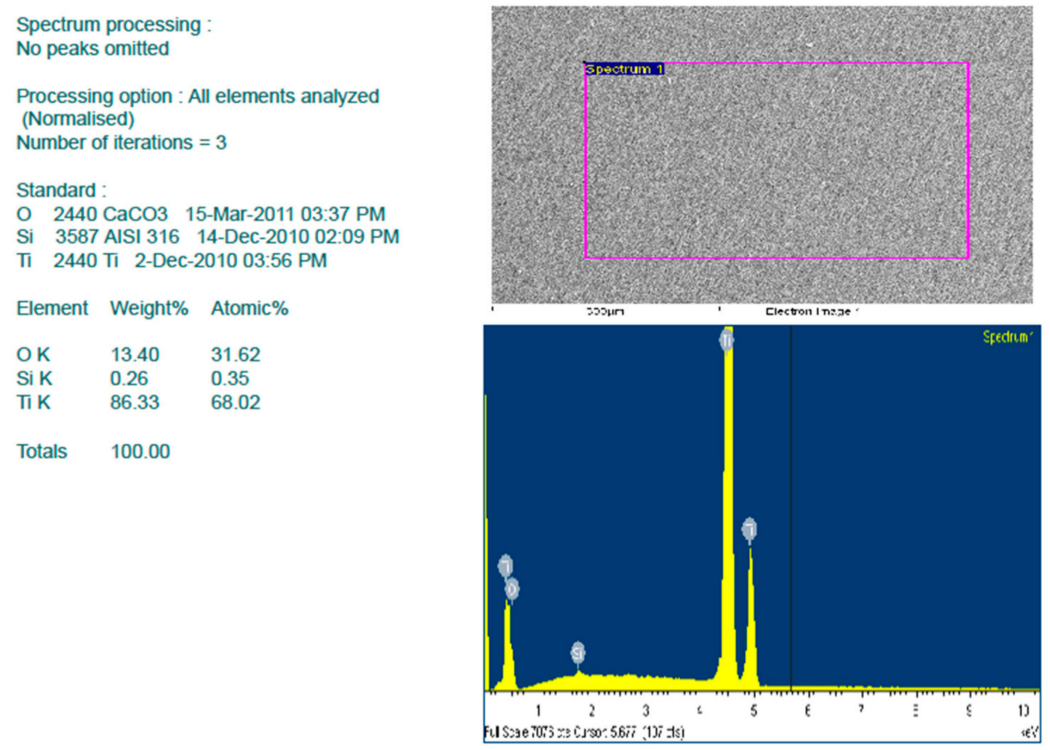

Figure 2. Surface chemical composition after gas oxidation of titanium.

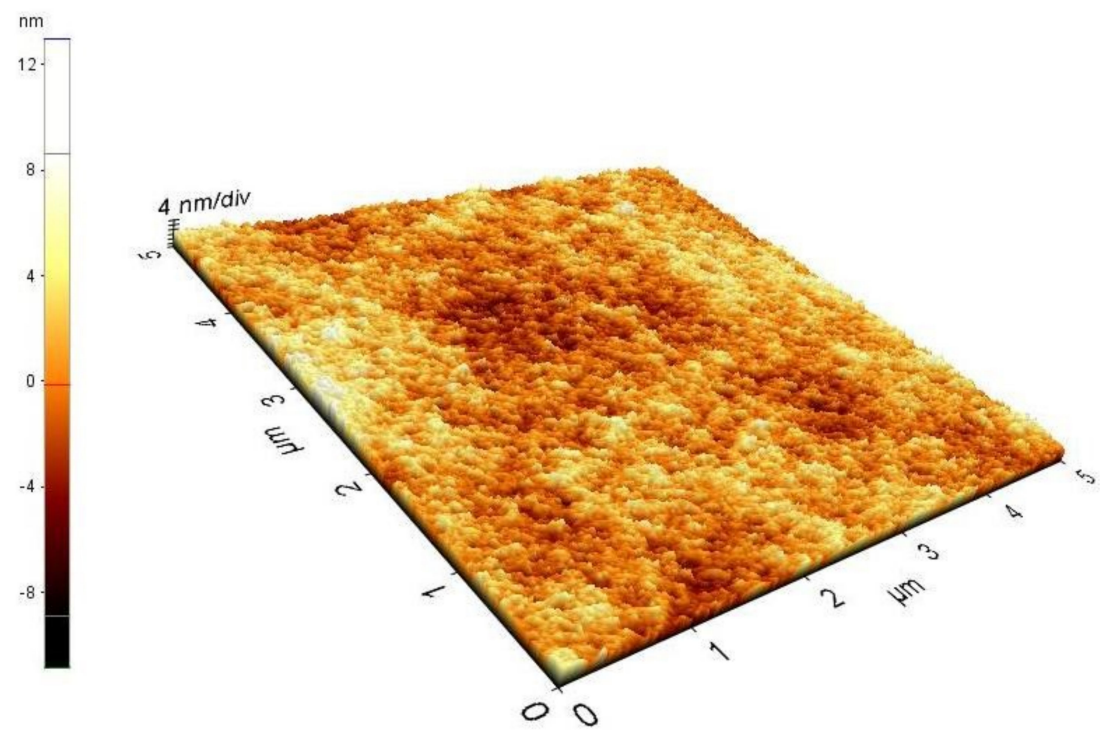

Figure 3. Topography of the deacetylation degree (DD) $87 \%$ sigma chitosan membrane. 


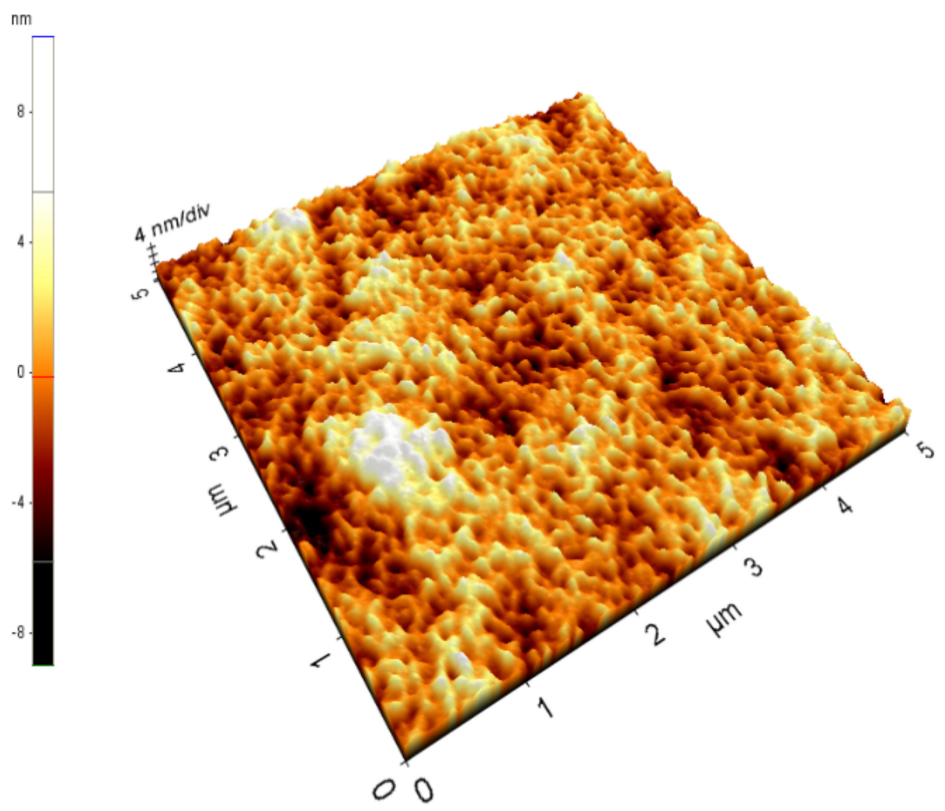

Figure 4. Topography of the DD $87 \%$ chitosan membrane.

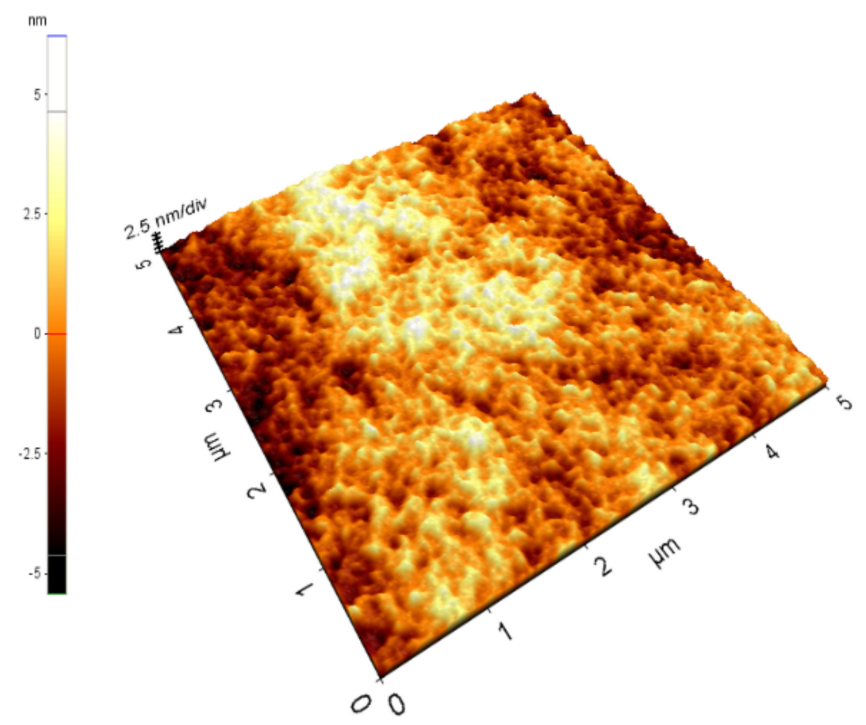

Figure 5. Topography of the DD 94\% chitosan membrane.

\subsection{Wettability of Chitosan Membranes}

The values of the contact angle are given in Figure 6. The contact angle slightly increased with the DD value. All membranes had hydrophilic properties.

Surface wettability is one of the physicochemical parameters that make it possible to estimate a material's quality and biocompatibility. Hydrophilicity is essential as it significantly influences the quality of cells' adherence and proliferation rate. The adhesion is stronger when the material demonstrates moderate hydrophilicity [36]. This effect results from increasing interaction between functional groups present on the material's surface and the cells. Here, the wettability angle increased with the DD value, but it remained comparable, in the range of $69.5^{\circ}-75.2^{\circ}$. The chitosan's origin also had no critical effect on the wettability angle. For the DD $87 \%$ sigma chitosan, the angle was $69.5^{\circ}$, and for the DD $87 \%$ chitosan it increased to only $73.6^{\circ}$. Likely, molecules of the same origin have a similar spatial structure, and, for the most part, only DD values as low as 50\%-60\% may differentiate the biological properties. 


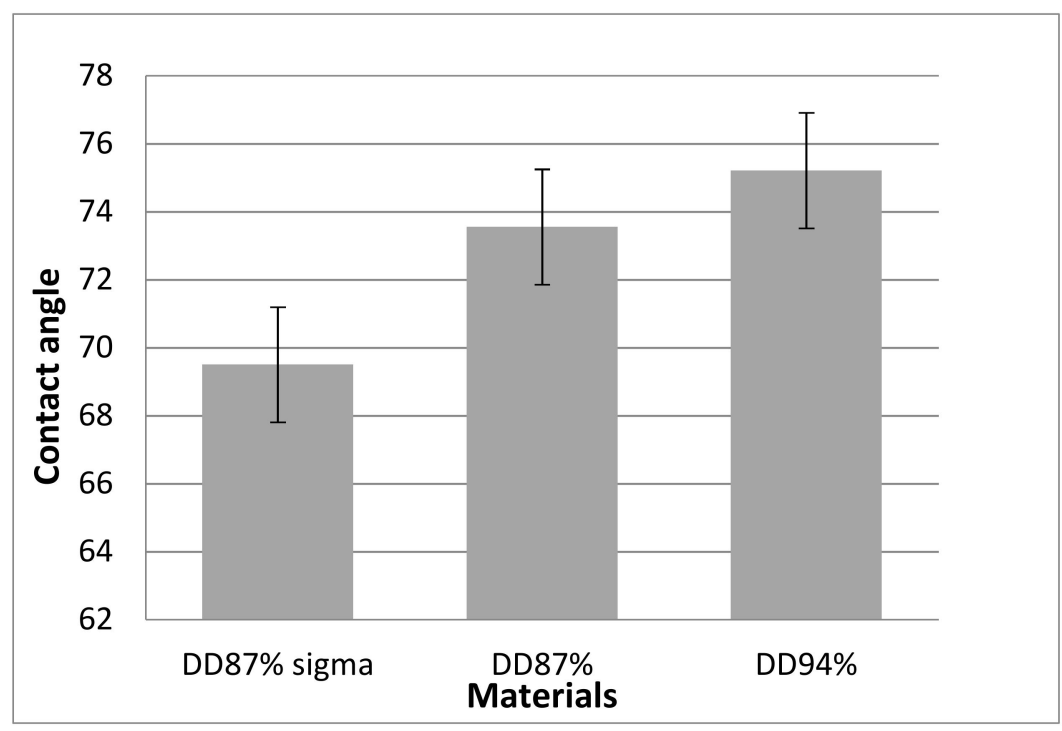

Figure 6. Contact angle for the tested chitosan membranes.

\subsection{Wear Resistance}

The results of the tests performed on the coatings on titanium samples are shown in Figures 7-9 as calculated by the machine software. For all tests, the friction coefficient changed between a value close to zero and about 16, the lowest being for the DD 87\% sigma coating. The penetration depth was similar for all coatings; about $10^{-5} \mu \mathrm{m}$ in a nanometric range. For the DD $87 \%$ sigma coating, the penetrator delved itself quickly, and the friction force became constant after an initial decrease. For the DD 87\% coating, the stepwise increase in friction force was followed by force stabilization, which may be explained by some irregularities of the surface. For the DD 94\% coating, the friction force was constant, likely because of the homogenous surface. All coatings remained on the titanium surface, demonstrating excellent adhesion to the substrate after the applied surface treatment and about a $0.08 \mathrm{mN}$ force value.

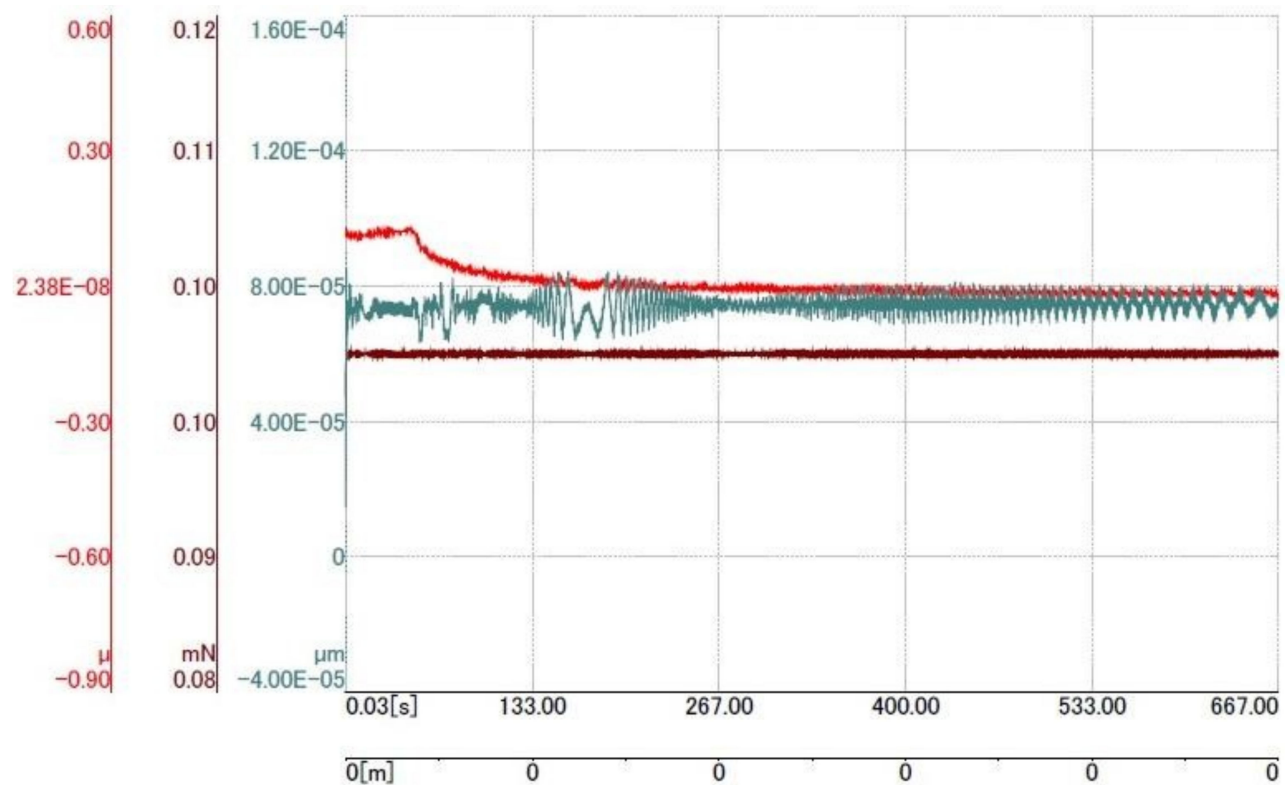

Figure 7. Results of wear tests for the chitosan of DD 87\% sigma coating: red color-change in friction coefficient with test time, green color-change in penetration depth $(\mu \mathrm{m})$, and brown color-load force, which was constant during the test. 


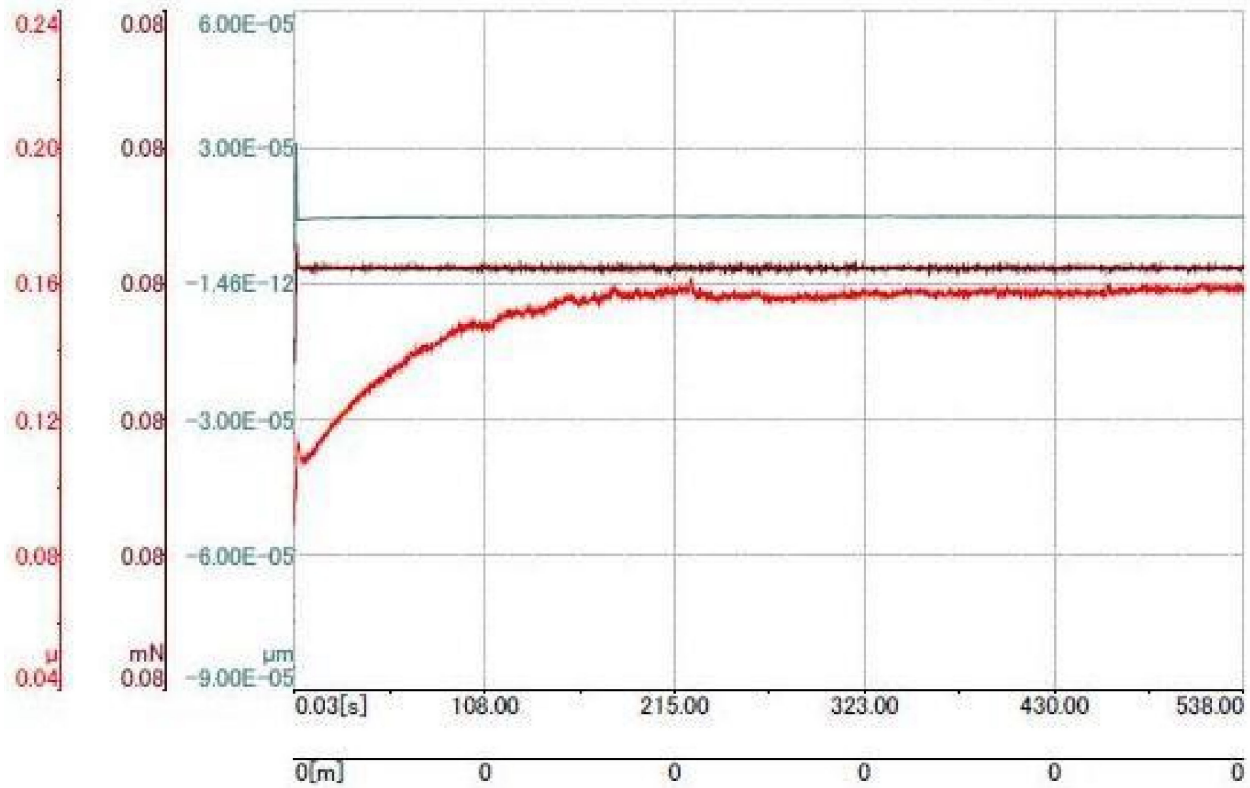

Figure 8. Results of wear tests for the chitosan of DD 87\% coating: red color-change in friction coefficient with test time, green color-change in penetration depth $(\mu \mathrm{m})$, and brown color-load force, which was constant during the test.

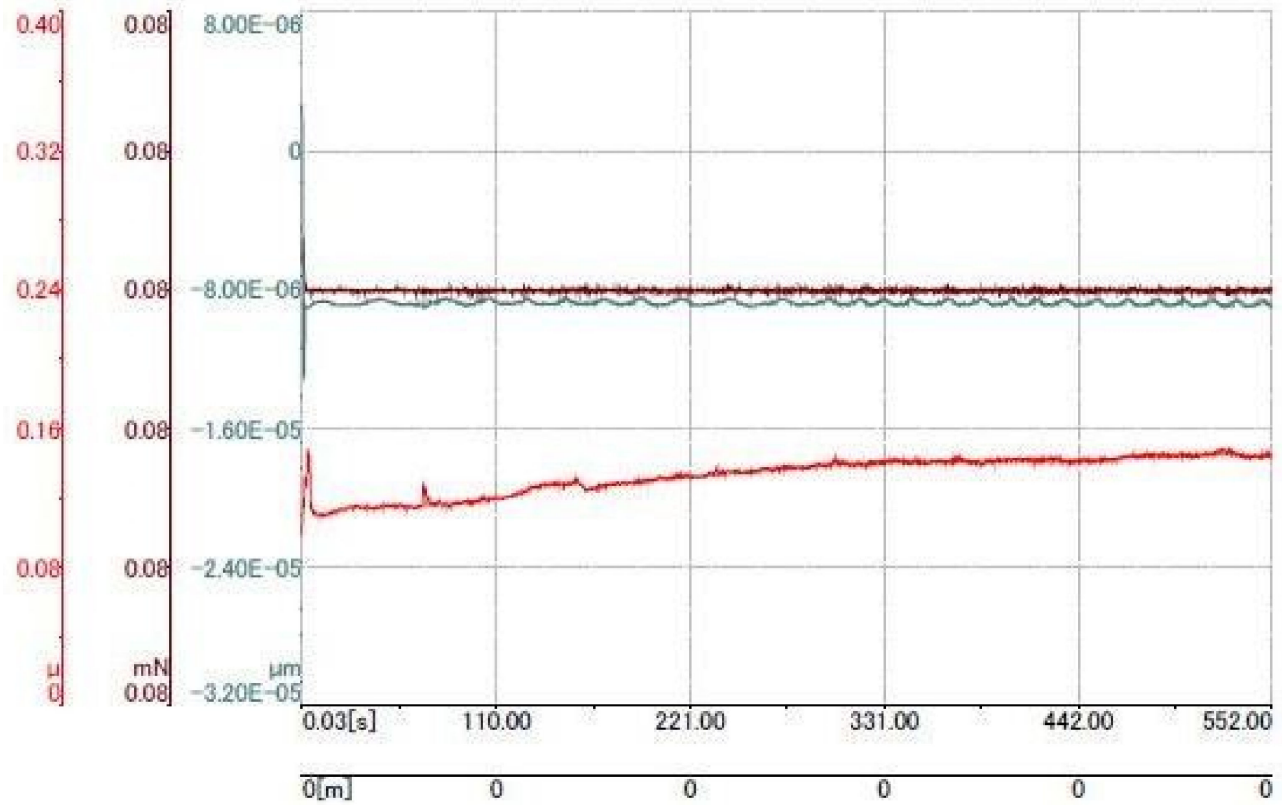

Figure 9. Results of wear tests for the chitosan of DD 94\% sigma coating: red color-change in friction coefficient with test time, green color-change in penetration depth $(\mu \mathrm{m})$, and brown color-load force, which was constant during the test.

\subsection{Biological Properties}

Figure 10 shows the cell growth after 24, 48, and $96 \mathrm{~h}$ in the culture vessel. The cells grew evenly. The morphology was proper for osteoblasts. 


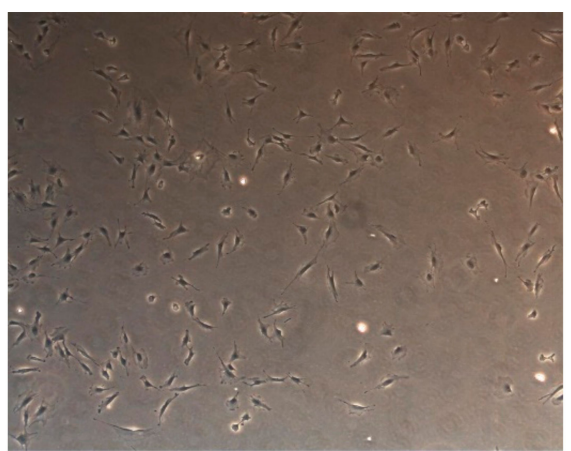

(a)

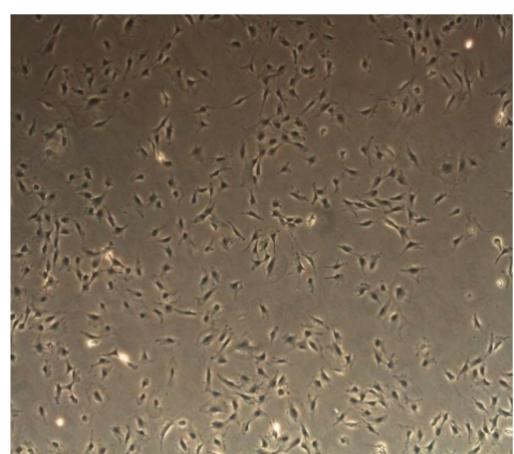

(b)

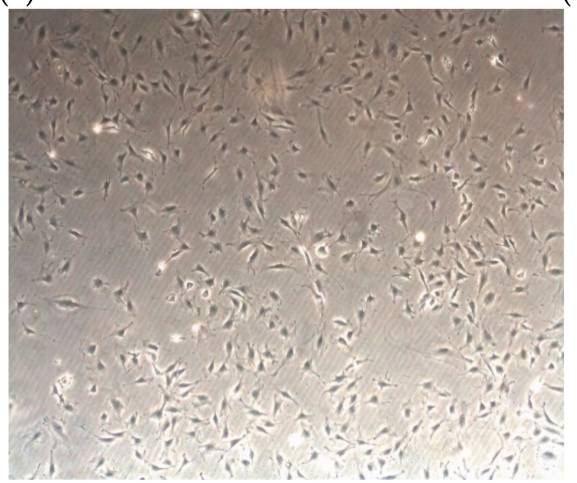

(c)

Figure 10. The cells on the culture vessel after (a) $24 \mathrm{~h},(\mathbf{b}) 48 \mathrm{~h}$, and (c) $72 \mathrm{~h}$ of exposure. Magnification 1000x.

The results of the tests of the proliferation of cells on the coatings are shown in Figures 11-13. The test results revealed good quantitative (number of cell nuclei) and qualitative (morphology of osteoblasts) results for titanium covered with coatings made of DD $87 \%$ and DD $94 \%$ chitosan prepared from shrimps. In the case of coatings made of DD 87\% sigma prepared from crabs, the number of cell nuclei was low, and the morphology of osteoblasts was improper. The cell proliferation was satisfactory. After seven days, they occupied $70 \%-80 \%$ of the surface with a distinct trend of further development. For the chitosan derived from crabs, no settlement followed by proliferation was observed so that such chitosan forms would not guarantee any bone growth. The chitosan's origin imposed then a very significant effect on biological properties, likely because of the diversified spatial structure and another molecule polarity. A better cell response may also be related to the lower molecular mass, but the effect of the chitosan's source of biological properties and origin have been exceptionally investigated to date. The osteoblasts on homogenous coatings made of the DD 87\% and DD 94\% chitosan were disorderly arranged, and titanium exhibited surface-oriented grooves on which the osteoblasts were present.

The degree of coverage of the titanium surface with chitosan coating was verified by a test based on the coloration of chitosan with Alizarin Red. The whole surface, except for the area on which the pincers were placed, was a red-brown color, proving the presence of a continuous coating of chitosan (Figure 14).

A seven-day period of cell culture may be insufficient to reliably determine the effects of DD value and chitosan origin on the formation of bone tissue. In spite of that, such a test time permits us to prove the biocompatibility and make a reasonable prognosis for bone tissue growth. The obtained results lead to a fair assumption that the DD value within the tested limits has no noticeable effect on the degree of implant osseointegration. In contrast, the chitosan's origin, which determines the spatial structure, molecular mass, and distribution of surface charge, may affect the osseointegration process significantly. 


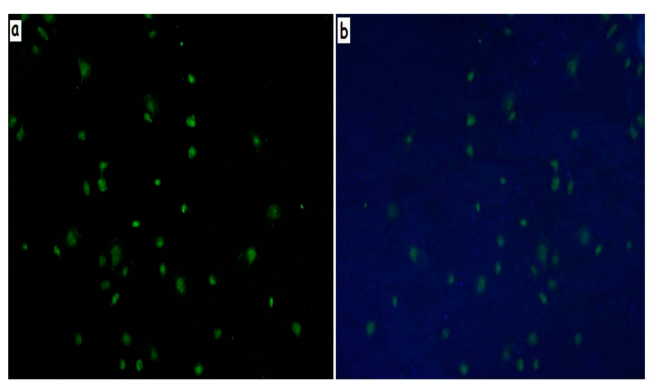

(a)

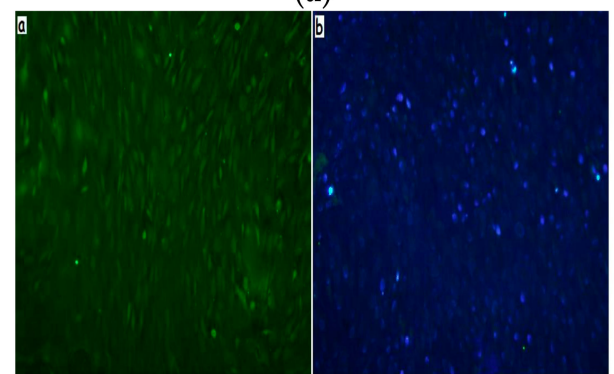

(c)

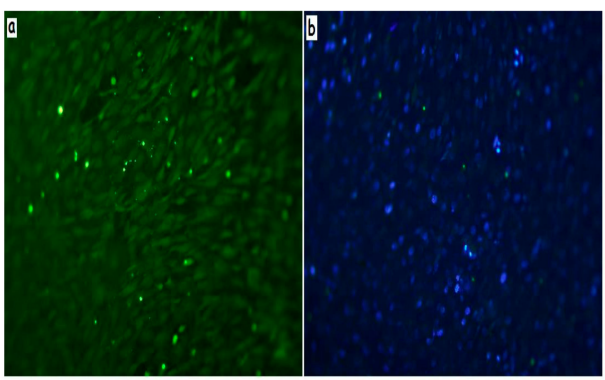

(b)

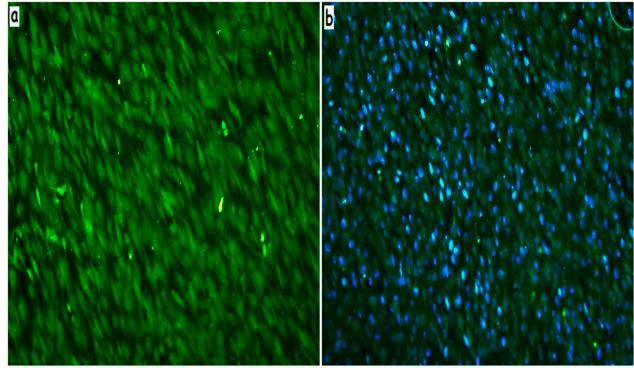

(d)

Figure 11. The chitosan coatings with osteoblasts after applying the reagents, carboxyfluorescein succinimidyl ester (CFSE; the green images or "a") and 4',6-Ddiamidino-2-phenylindole (DAPI; the blue images or " $b^{\prime \prime}$ ): (a) DD 87\% sigma, (b) DD 87\%, (c) DD 94\%, and (d) oxidized titanium. Magnification 25×.

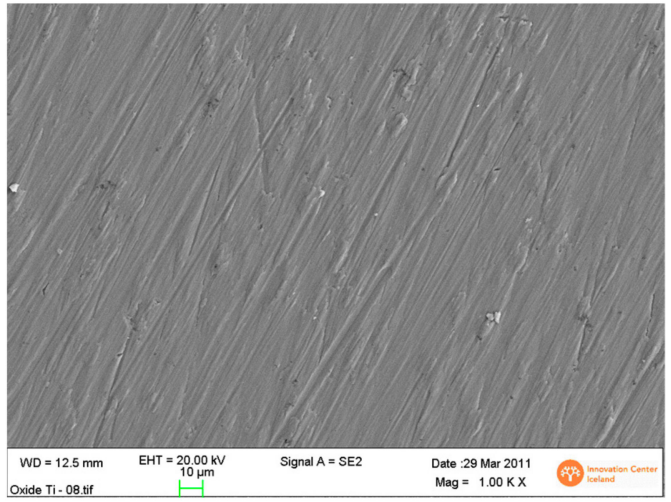

(a)

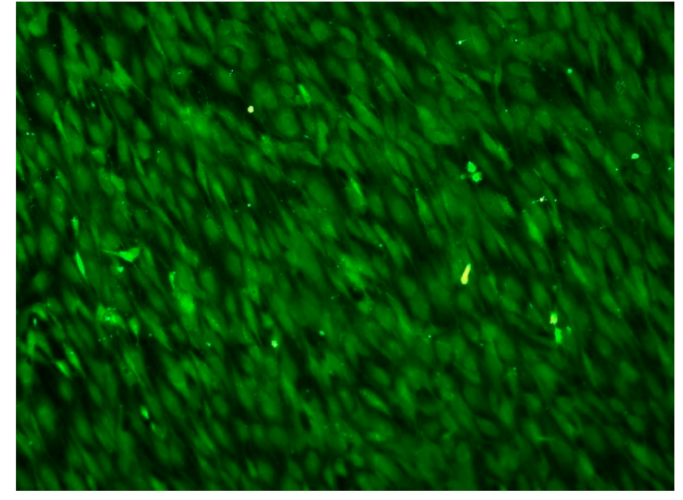

(b)

Figure 12. The images of surfaces: (a) surface of gas-oxidized titanium, and (b) surface of gas-oxidized titanium with a cell detected with CFSE reagent. Magnification 500×.

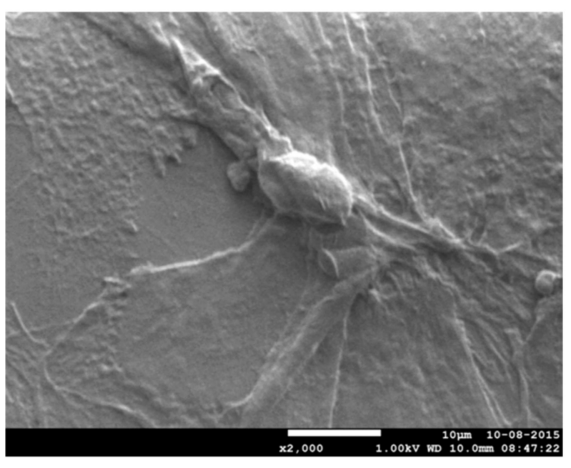

(a)

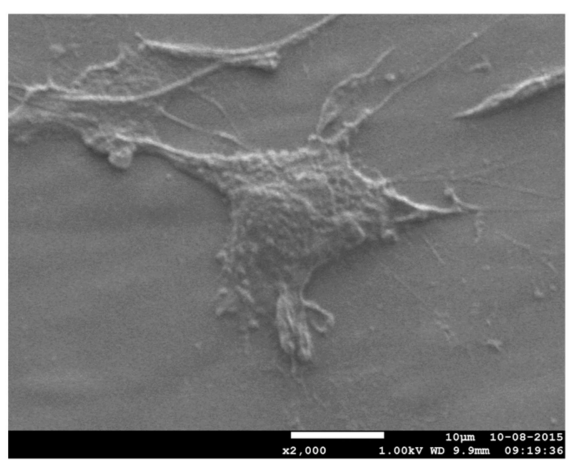

(b)

Figure 13. Osteoblasts on titanium surface coated with chitosan of shrimp origin: (a) DD 87\%, and (b) DD 94\%. Magnification 2000× (scale bar $10 \mu \mathrm{m}$ ). 


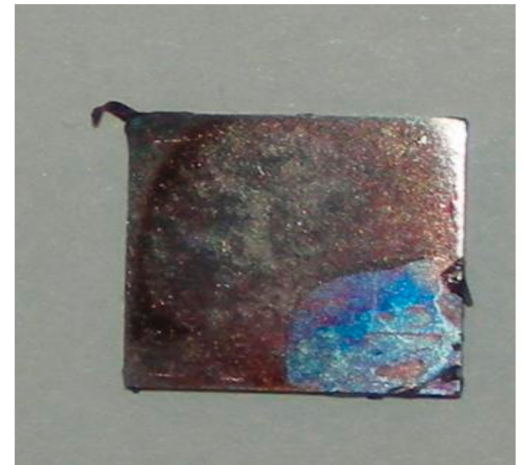

(a)

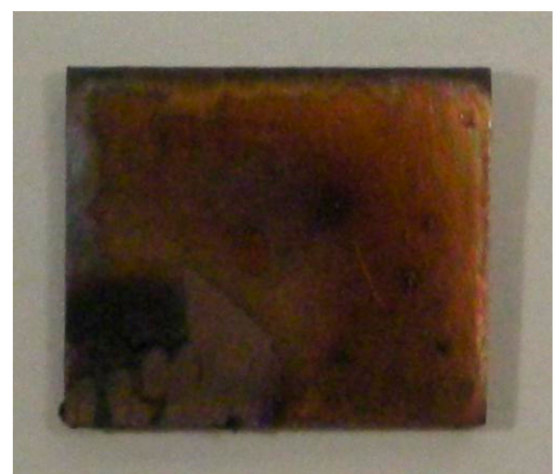

(b)

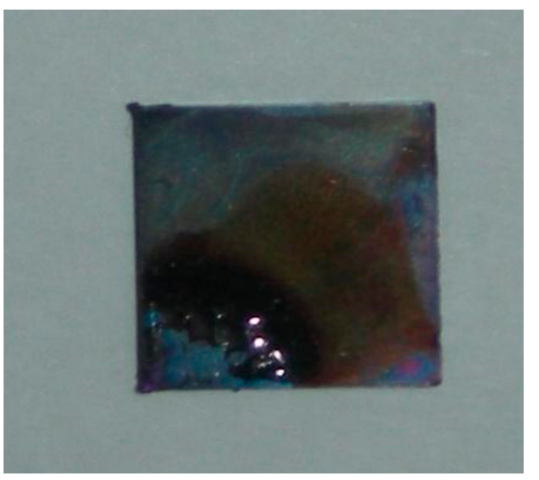

(c)

Figure 14. Chitosan coatings after colorization with Alizarin Red: (a) DD 87\% sigma, (b) DD 87\%, and (c) DD 94\%. Magnification: 6 or $8 \times($ b).

\section{Conclusions}

Chitosan coatings on a titanium substrate possess the biological properties under in vitro conditions substantially dependent on the chitosan's origin.

A deacetylation degree in the range of $87-94 \%$ and chitosan sources did not affect the surface roughness more significantly, which remained in a nanometric range.

Chitosan derived from shrimps had a higher biocompatibility and a greater biological response for the MC3T3-E1 cells under in vitro conditions than the chitosan from crabs. The reason may be its lower molecular mass, different spatial structure, different surface charge, distribution, and order of radicals.

A deacetylation degree in the range of $87-94 \%$ did not affect the biological properties of chitosan coatings.

Author Contributions: Conceptualization, methodology, software, validation, formal analysis, investigation, resources, data curation, writing, project administration, and funding acquisition, M.S.-M.; writing-review and editing and supervision, A.Z. All authors have read and agreed to the published version of the manuscript.

Funding: This research was funded by the Polish National Research Center. PRELUDIUM grant number: 2012/05/N/ST8/02909.

Acknowledgments: The assistance of several colleagues from Reykjavik University, the Innovation Center Iceland, Blood Bank, and Genis, Iceland, is gratefully acknowledged. We express our gratitude to the CSM Poland for the opportunity to perform the nanotests. The chitosan powders were delivered by the Blood Bank, Landspitali University Hospital (Reykjavik, Iceland).

Conflicts of Interest: The authors declare no conflicts of interest.

\section{References}

1. Xu, C.; Lei, C.; Meng, L.; Wang, C.; Song, Y. Chitosan as a barrier membrane material in periodontal tissue regeneration. J. Biomed. Mater. Res. B Appl. Biomater. 2012, 100, 1435-1443. [CrossRef] [PubMed] 
2. Naira, L.S.; Laurencin, C.T. Biodegradable polymers as biomaterials. Prog. Polym. Sci. 2007, 329, $762-798$. [CrossRef]

3. Muzzarelli, R.A.A. Chitins and chitosans for the repair of wounded skin, nerve, cartilage and bone. Carbohydr. Polym. 2012, 76, 167-182. [CrossRef]

4. Jayakumar, R.; Prabaharan, M.; Sudheesh Kumar, P.T.; Nair, S.V.; Tamura, H. Biomaterials based on chitin and chitosan in wound dressing applications. Biotechnol. Adv. 2011, 2, 323-337. [CrossRef] [PubMed]

5. Qin, C.; Li, H.; Qiao, Q.; Liu, Y.; Zhu, J.; Du, Y. Water-solubility of chitosan and its microbial activity. Carbohydr. Polym. 2006, 63, 367-374. [CrossRef]

6. Lieder, R. Chitosan and Chitosan Derivatives in Tissue Engineering and Stem Cell Biology. Ph.D. Thesis, School of Science and Engineering, Reykjavik University, Reykjavik, Iceland, 2013.

7. Muzzarelli, R.A.A.; Boudrant, J.; Meyer, D.; Manno, M.; DeMarchis, M.; Paoletti, M.G. Current views on fungal chitin/chitosan, human chitinases, food preservation, glucans, pectins and inulin: A tribute to Henri Braconnot, precursor of the carbohydrate polymers science, on the chitin bicentennial. Carbohydr. Polym. 2012, 87, 995-1012. [CrossRef]

8. Liu, X.; Ma, L.; Mao, Z.W.; Gao, C. Chitosan-based biomaterials for tissue repair and regeneration. Adv. Polym. Sci. 2011, 244, 81-128.

9. Bottino, M.C.; Thomas, V.; Schmidt, H.; Vohra, Y.K.; Chu, T.M.G.; Kolowik, M.J.; Janowski, G.M. Recent advances in the development of GTR/GBR membranes for periodontal regeneration-A materials perspective. Dent. Mater. 2012, 28, 703-721. [CrossRef]

10. Bottino, M.C.; Thomas, V. Membranes for Periodontal Regeneration-A Materials Perspective. Front. Oral Biol. 2015, 17, 90-100.

11. Kong, M.; Chen, X.G.; Xing, K.; Park, H.J. Antimicrobial properties of chitosan and modification: A state of the art review. Int. J. Food Microbiol. 2010, 144, 51-63. [CrossRef]

12. Fernandes, I.P.; Amaral, J.S.; Pinto, V.; Ferreira, M.J. Development of chitosan-based antimicrobial leather coatings. Carbohydr. Polym. 2013, 98, 1229-1235. [CrossRef] [PubMed]

13. Li, X.; Ma, X.Y.; Feng, Y.F.; Wang, L.; Wang, C. A novel composite scaffold consisted of porous titanium and chitosan sponge for load-bearing applications: Fabrication, characterization and cellular activity. Compos. Sci. Technol. 2015, 117, 78-84. [CrossRef]

14. Di Martino, A.; Sittinger, M.; Risbud, M.V. Chitosan: A versatile biopolymer for orthopaedic tissue-engineering. Biomaterials 2005, 26, 5983-5990. [CrossRef] [PubMed]

15. Thein-Han, W.W.; Misra, R.D.K. Biomimetic chitosan-nanohydroxyapatite composite scaffolds for bone tissue engineering. Acta Biomater. 2009, 5, 1182-1197. [CrossRef] [PubMed]

16. Prabaharan, M. Review Paper: Chitosan Derivatives as Promising Materials for Controlled Drug Delivery. J. Biomater. Appl. 2008, 23, 15-36. [CrossRef] [PubMed]

17. Busilacchi, A.; Gigante, A.; Mattioli-Belmonte, M.; Manzotti, S.; Muzarelli, S.A. Chitosan stabilizes platelet growth factors and modulates stem cell differentiation toward tissue regeneration. Carbohydr. Polym. 2013, 98, 665-676. [CrossRef]

18. Paluszkiewicz, C.; Weselucha-Birczynska, A.; Stodolak-Zych, E.; Hasik, M. 2D IR correlation analysis of chitosan-MMT nanocomposite system. Vib. Spectrosc. 2012, 5, 185-188. [CrossRef]

19. Abueva, C.D.G.; Padalhin, A.R.; Min, Y.K.; Lee, B.T. Preformed chitosan cryogel-biphasic calcium phosphate: A potential injectable biocomposite for pathologic fracture. J. Biomater. Appl. 2015, 30, 182-192. [CrossRef]

20. Chang, C.; Peng, N.; He, M.; Teramoto, Y. Fabrication and properties of chitin/hydroxyapatite hybrid hydrogels as scaffold nano-materials. Carbohydr. Polym. 2013, 91, 7-13. [CrossRef]

21. Muzzarelli, R.A.A.; Greco, F.; Busilacchi, A.; Solazzo, V. Chitosan, hyaluronan and chondroitin sulfate in tissue engineering for cartilage regeneration: A review. Carbohydr. Polym. 2012, 89, 723-739. [CrossRef]

22. Ma, S.; Chen, Z.; Qiao, F.; Sun, Y. Guided bone regeneration with tripolyphosphate cross-linked asymmetric chitosan membrane. J. Dent. 2014, 42, 1603-1612. [CrossRef] [PubMed]

23. Cheng, X.; Li, Y.; Zuo, Y.; Zhang, L. Properties and in vitro biological evaluation of nano-hydroxyapatite/ chitosan membranes for bone guided regeneration. Mater. Sci. Eng. C 2009, 29, 29-35.

24. Nagahama, H.; Maeda, H.; Kasjiki, T.; Jayakumar, R.; Furuike, H.; Tamura, H. Preparation and characterization on novel chitosan/gelatin membranes using chitosan hydrogel. Carbohydr. Polym. 2009, 76, 255-260. [CrossRef] 
25. Bumgardner, J.D.; Wiser, R.; Elder, S.H.; Jouett, R.; Yang, Y.; Ong, J.L. Contact angle, protein adsorption and osteoblast precursor cell attachment to chitosan coatings bonded to titanium. J. Biomater. Sci. Polym. Ed. 2003, 14, 1401-1409. [CrossRef] [PubMed]

26. Bumgardner, J.D.; Wiser, R.; Gerard, P.D.; Bergin, P.; Chestnutt, B.; Marin, M.; Ramsey, V.; Elder, S.H.; Gilbert, J.A. Chitosan: Potential use as a bioactive coating for orthopaedic and craniofacial/dental implants. J. Biomater. Sci. Polym. Ed. 2003, 14, 423-428. [CrossRef]

27. Yuan, Y.; Chesnutt, B.M.; Wright, L.; Haggard, W.O.; Bumgardner, J.D. Mechanical property, degradation rate, and bone cell growth of chitosan coated on titanium influenced by degree of deacetylation of chitosan. J. Biomed. Mater. Res. B Appl. Biomater. 2008, 86, 245-252. [CrossRef]

28. Martin, H.J.; Schulz, K.H.; Bumgardner, J.D.; Walters, K.B. An XPS study on the attachment of triethoxsilylbutyraldehyde to two titanium surfaces as a way to bond chitosan. Appl. Surf. Sci. 2008, 254, 4599-4605. [CrossRef]

29. Martin, H.J.; Schulz, K.H.; Bumgardner, J.D.; Schneider, J.A. Enhanced bonding of chitosan to implant quality titanium via four treatment combinations. Thin Solid Films 2008, 516, 6277-6286. [CrossRef]

30. Jun, S.H.; Lee, E.J.; Yook, S.W.; Kim, H.E.; Kim, H.W.; Koh, Y.H. A bioactive coating of a silica xerogel/chitosan hybrid on titanium by a roomtemperature sol-gel process. Acta Biomater. 2010, 6, 302-307. [CrossRef]

31. Mishra, S.K.; Kannan, S. Development, mechanical evaluation and surface characteristics of chitosan/polyvinyl alcohol based polymer composite coatings on titanium metal. J. Mech. Behav. Biomed. Mater. 2014, 40, 314-324. [CrossRef]

32. Ghimire, N.; Luo, J.; Tang, R.; Sun, Y.; Deng, Y. Novel anti-infective activities of chitosan immobilized titaniumsurface with enhanced osteogenic properties. Colloids Surf. B Biointerfaces 2014, 122, 126-133. [CrossRef] [PubMed]

33. Lieder, R.; Darai, M.; Thor, M.B.; Ng, C.H.; Einarsson, J.M.; Gudmundsson, S.; Helgason, B.; Gaware, V.S.; Másson, M.; Gíslason, J.; et al. In Vitro bioactivity of different degree of deacetylation chitosan, a potential coating material for titanium implants. J. Biomed. Res. A 2012, 100, 3392-3399.

34. Chatelet, C.; Damour, O.; Domar, A. Influence of the degree of acetylation on some biological properties of chitosan films. Biomaterials 2001, 22, 261-268. [CrossRef]

35. ASTM 265-20 Standard Specification for Titanium and Titanium Alloy Strip, Sheet, and Plate; ASTM: West Conshohocken, PA, USA, 2019.

36. Ellingsen, J.E.; Johansson, C.B.; Wennerberg, A.; Holmén, A. Improved retention and bone-to-implant contact with fluoride-modified titanium implants. Int. J. Oral Maxillofac. Implants 2004, 19, 659-666. [PubMed] 